\title{
The expanding role of lipid II as a target for lantibiotics
}

\author{
Nathaniel I Martin \& \\ Eefjan Breukink ${ }^{\dagger}$ \\ ${ }^{\dagger}$ Author for correspondence \\ Utrecht University, \\ Department of Biochemistry \\ \& Membranes, Padualaan 8 , \\ 3584 CH Utrecht, \\ The Netherlands \\ e.j.breukink@chem.uu.nl
}

\begin{abstract}
Lipid II is an essential cell-wall precursor required for the growth and replication of both Gram-positive and Gram-negative bacteria. Compounds that use lipid II to selectively target bacterial cells for destruction represent an important class of antibiotics. Clinically, vancomycin is the most important example of an antibiotic that operates in this manner. Despite being considered the 'antibiotic drug of last resort', significant bacterial resistance to vancomycin now manifests itself worldwide. In this paper we review recent progress made in understanding the lipid II-associated antibacterial characteristics of various naturally occurring compounds, with particular focus on the lantibiotic peptides.
\end{abstract}

Keywords: antibiotic, lacticin 3147, lantibiotic, lantibiotic mode of action, lipid II, nisin, peptidoglycan

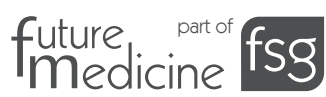

Antibiotics revolutionized medicine in the early 20th Century and continue to be a cornerstone in the battle against infectious disease. The accelerated appearance of drug-resistant bacteria over the past two decades, however, presents a serious threat to human health and fuels the demand for the development of new antibiotics. The sequencing of the first complete bacterial genome in 1995 heralded a new era of hope for antibacterial drug discovery. Despite the promise for genomic approaches, useful antibiotics have not emerged using these strategies [1]. This has led to a renewed interest in natural products as a source for antimicrobials. This review examines antibiotics derived from natural sources, specifically compounds belonging to the lantibiotic family that utilize lipid II in their antibacterial modes of action.

Bacteria synthesize peptidoglycan, starting from the common building block, lipid II. Peptidoglycan is the continuous, covalent, macromolecular structure that provides the strength and rigidity to the cell walls of both Gram-positive and Gram-negative bacteria (Figure 1). This polymeric network is comprised of alternating amino sugars, $\mathrm{N}$-acetylglucosamine (GlcNAc) and $N$-acetylmuramic acid (MurNAc) [2]. These glycan polymer chains are cross-linked by a pentapeptide, typically with the sequence L-alanyl- $\gamma$-D-glutamyl-diaminopimelyl (or L-lysyl)-D-alanyl-D-alanine, which is attached to the MurNAc sugar. The glycosidic linkages in peptidoglycan are generated by bifunctional high molecular weight penicillin binding proteins (PBPs) or monofunctional transglycosylases. Two of these high molecular weight PBPs have recently been characterized at the structural level $[3,4]$ and represent an, as of yet, unexploited target for antibiotic development. Alternatively, the enzyme activity responsible for cross-linking the pentapeptide units in peptidoglycan has historically been among the most important antibiotic targets. The penicillins, cephalosporins, carbapenems and monobactams all operate by inhibition of the peptidoglycan-cross-linking transpeptidases [5].

As mentioned above, lipid II is the fundamental building block from which bacteria synthesize peptidoglycan. Each lipid II monomer contains the GlcNAc-MurNAc disaccharide and pentapeptide as well as a C55 carbon chain attached to the disaccharide via a pyrophosphate linkage (Figure 2).

The pathway by which lipid II is biosynthesized has been the subject of previous reviews [6,7] and is here described in brief (Figure 3). Lipid II assembly occurs on the cytoplasmic side of the bacterial cell membrane, where the UDP-MurNAcpentapeptide is coupled to the membrane associated C55 lipid-phosphate by the action of the membrane protein MraY, to yield the intermediate lipid I. Addition of a GlcNAc sugar to lipid I is catalyzed by the membrane-associated enzyme MurG, providing lipid II. At this stage the intact lipid II monomer is translocated across the plasma membrane and is delivered to the periplasmic (exterior) side of the bacterial cell for incorporation into the growing peptidoglycan network. While the mechanism by which this translocation occurs is unknown, recent evidence has shown that it is not a spontaneous process and may be coupled to transglycosylation on the periplasmic cell surface [8].

The cell wall of Gram-positive bacteria contains multiple layers of peptidoglycan $(\sim 20)$ while Gram-negative bacteria require a thinner 


\section{Figure 1. Peptidoglycan layer in the bacterial cell wall.}

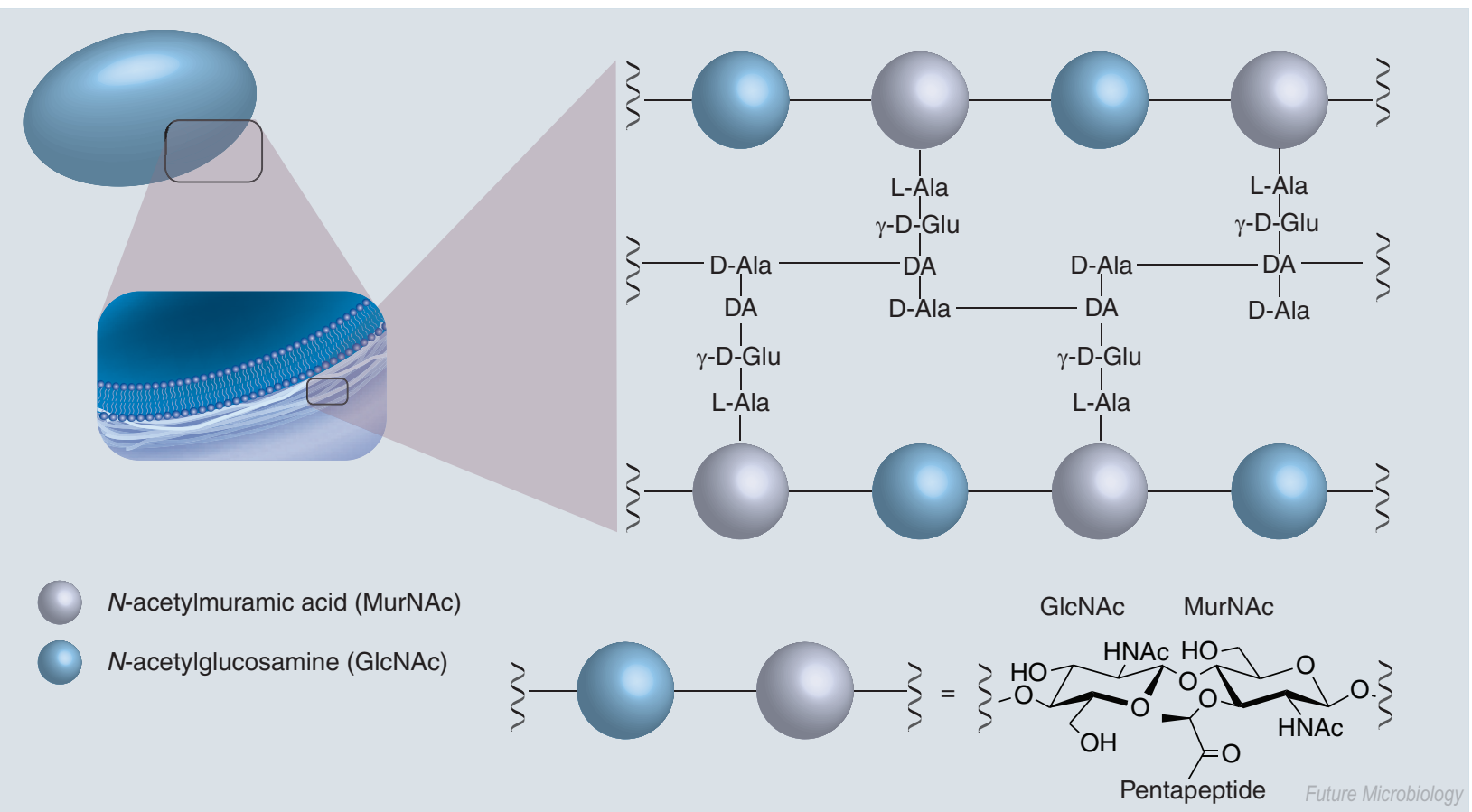

DA: Diamino acid (diaminopimelate or lysine).

cell wall, estimated to be 1.5 layers thick [9]. Despite the need for a continuous supply of lipid II, there exist approximately only 2000 intact molecules of this essential building block in a Gram-negative cell at any given time. This is likely due to the limited amount of C55 phospholipid (estimated to be $2 \times 10^{5}$ molecules per cell $\left.[10,11]\right)$ available for lipid II synthesis inside the cell and transport across the bacterial membrane. This suggests

\section{Figure 2. Structure of lipid II with the specific recognition elements for vancomycin and nisin indicated.}

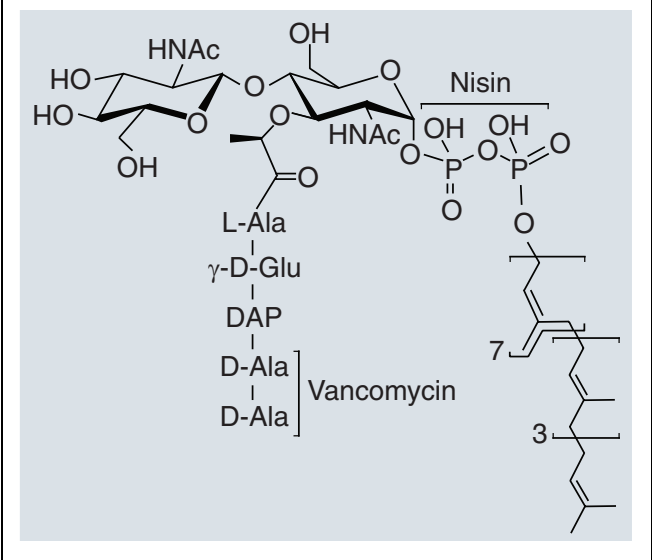

that the process by which lipid II is synthesized and incorporated into peptidoglycan is dynamic with respect to the C55 phopholipid (turnover rate for lipid II incorporation is estimated to be 1-3 transfers/sec/C55 phospholipid [12]). Given that bacteria rely on a relatively small amount of available lipid II, the targeted exploitation of this cycle presents a promising avenue for antibiotic discovery and development. In the subsequent sections we describe those antibiotics known to act by interfering with the lipid II cycle, as well as the adaptive resistance mechanisms that bacteria have developed to compensate.

\section{Vancomycin: the pre-eminent lipid II-binding antibiotic}

The first identified and most studied example of an antibiotic with a lipid II-specific mode of action is vancomycin (Figure 4a). Discovered in 1956, vancomycin was isolated from the soil bacterium Amycolatpsis orientalis and has been shown to have a broad spectrum of activity [13]. Vancomycin, and the structurally similar teicoplanin (Figure $4 \mathrm{~b}$ ), belong to the glycopeptide family of antibiotics and have been approved for human clinical use. Both contain a nonribosomally synthesized peptide aglycone as well as a number 
Figure 3. Lipid II biosynthesis and incorporation into peptidoglycan.

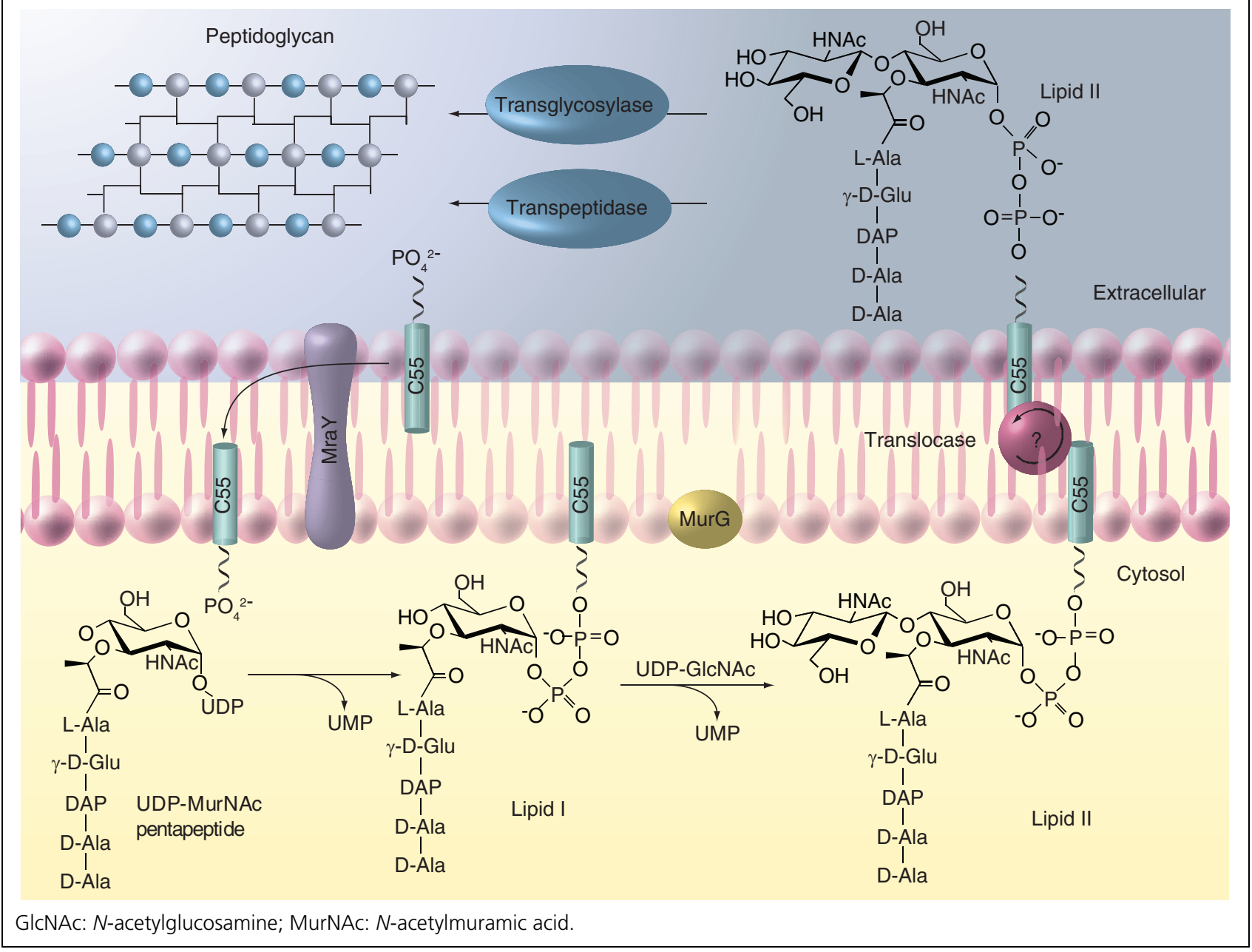

of associated carbohydrate groups (and a C10 lipid in the case of teicoplanin). The aglycone of each contains the unnatural amino acids hydroxyphenylglycine and dihydroxyphenylglycine, the biosynthetic details of which have recently been described [14]. Cyclization of the peptide backbone was also recently shown to be the result of three unique enzymatic oxidative couplings $[15,16]$. The resulting polycyclic scaffold provides vancomycin and teicoplanin with a structural rigidity that contributes to their lipid II-binding ability [17-19]. Interaction of vancomycin with the D-Ala-D-Ala moiety of the lipid II pentapeptide (as illustrated in Figures $2 \&$ aa) was first observed using chromatographic, electrophoretic and differential ultraviolet spectral approaches [20,21], and this was later confirmed by nuclear magnetic resonance spectroscopy $[18,22]$. These experiments employed small fragments of the lipid II pentapeptide and recent investigations using a more representative lipid II species have suggested that there may be additional complexity to the interaction [23].
As illustrated in Figure 4a, vancomycin binds to the sequence D-Ala-D-Ala through a specific network of five hydrogen bonds. By doing so, vancomycin effectively sequesters lipid II and prevents its normal incorporation into the growing peptidoglycan network, which ultimately leads to cell death. In response, certain bacteria have adapted to this mechanism of action and are capable of mutating the terminal D-Ala residue to D-lactate in the lipid II pentapeptide [24]. This mutation greatly reduces the affinity of vancomycin for lipid II and leads to a resistant strain [25-27]. In response, drug makers are now developing new semisynthetic glycopeptides including dalbavancin [28], telavancin [29] and oritavancin [30]. While retaining the vancomycin aglycone, these second generation glycopeptides are elaborated with various hydrophobic groups on the disaccharide moiety, rendering the compounds active against otherwise resistant organisms. In addition, a small number of novel, nonribosomal peptide 


\section{Figure 4. The glycopeptide antibiotics vancomycin and teicoplanin.}

(A)

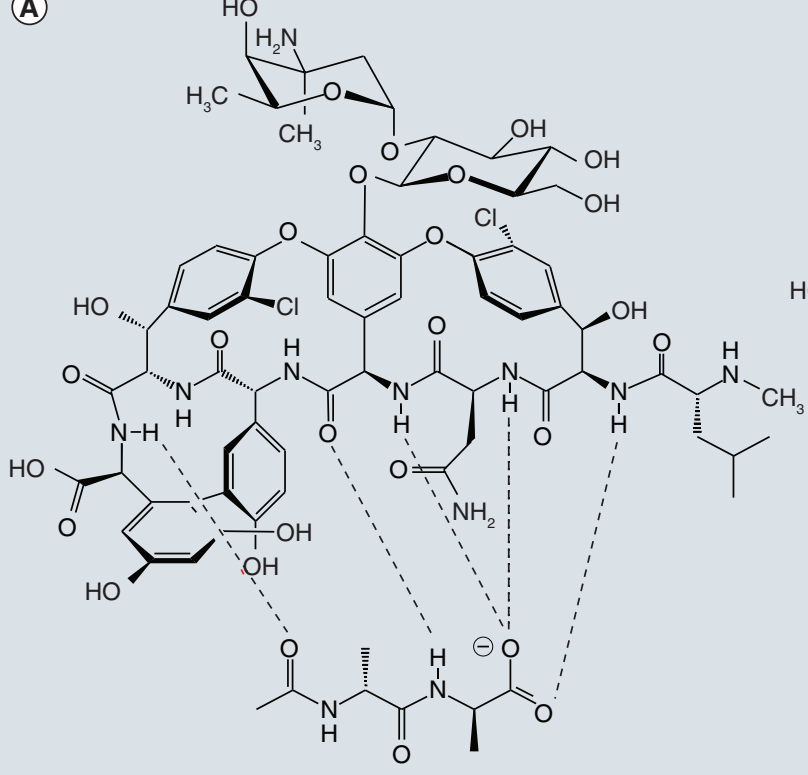

(B)

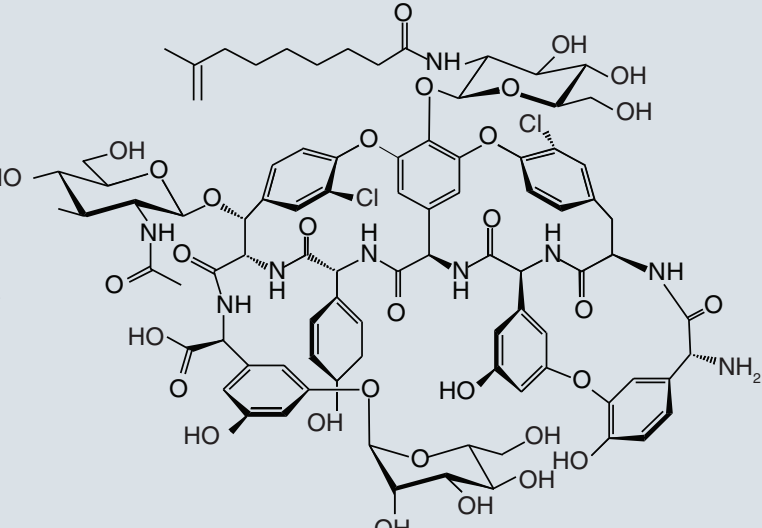

$\mathrm{OH}$

(A) Vancomycin and its specific interaction with the D-Ala-D-Ala moiety of the lipid II pentapeptide (nuclear magnetic resonance structure determined using $\mathrm{N}$-acetyl-D-Ala-D-Ala as shown). (B) Teicoplanin.

antibiotics have recently been described, including the ramoplanins [31-33], mannopeptimycins [34,35], plusbacins [36,37] and katanosins [38]. While these compounds have all been described as lipid II-binding antibiotics [39], they will not be discussed in further detail here with the remaining focus of this review being the lantibiotic class of antibiotics.

\section{Lantibiotics}

In addition to conventional small molecule antibiotics, another family of lipid II-targeting antimicrobial agents, the lantibiotics, is rapidly gaining recognition. Lantibiotics are small (2-6 kDa) ribosomally synthesized bacterial defense peptides that contain extensive posttranslational modifications $[40,41]$. The discovery of the first lantibiotic, nisin (Figure 5), in 1928 [42], predates Flemming's discovery of penicillin and, to date, approximately 50 different lantibiotics have been identified from approximately 30 different bacteria. Over the past 20 years there has been an increasing interest in such compounds as possible preservative agents for food and as potential supplements or replacements for currently used antibiotics. Many lantibiotics show promising activity towards a variety of pathogenic bacteria including methicillinresistant Staphylococcus aureus (MRSA) and vancomycin-resistant Enterococcus (VRE) [43]. Detailed descriptions pertaining to the activity spectra and therapeutic potential of lantibiotics have been previously described [39,44-48].

The lantibiotic peptides can be classified based upon a number of features including size, shape, charge and mode of action $[40,49]$ and have traditionally been subdivided into two major groups - the type A and B lantibiotics - that comprise peptides with straight-chain and globular structures, respectively [50]. Additionally, a third class, the two-component lantibiotics, is now gaining recognition wherein two structurally different peptides act synergistically to kill target bacteria. In the following sections we describe the progress made in understanding the biosynthesis and modes of action of the major subgroups of lantibiotics.

\section{Lantibiotic biosynthesis}

Nisin is the most thoroughly studied lantibiotic and contains a number of unique post-translational modifications common to all lantibiotics (Figure 5) [51,52]. These include the dehydration of Ser and Thr residues to dehydroalanine (Dha) and dehydrobutyrine (Dhb), respectively, with subsequent cyclization by conjugate addition of Cys residues to Dha and Dhb, generating the thioether cross-links 
lanthionine (Lan) and methyllanthionine (MeLan), respectively. These latter structures have given lantibiotics their family name [53]. Lantibiotics are ribosomally synthesized as prepeptides and then enzymatically modified followed by proteolytic removal of a leader peptide to generate the active species with concomitant export from the cell [41]. Recently, the biosynthetic details of a number of lantibiotics including nisin have been investigated [54,55]. This work has shown that in the biosynthesis of nisin, two separate enzymes carry out the dehydration (NisB) and cyclization (NisC) reactions, prior to export and leader peptide removal by translocase (NisT) and protease (NisP) enzymes. Analogous enzyme systems have also been reported for a number of other lantibiotics [56-59].

\section{Figure 5. Biosynthesis of nisin.}

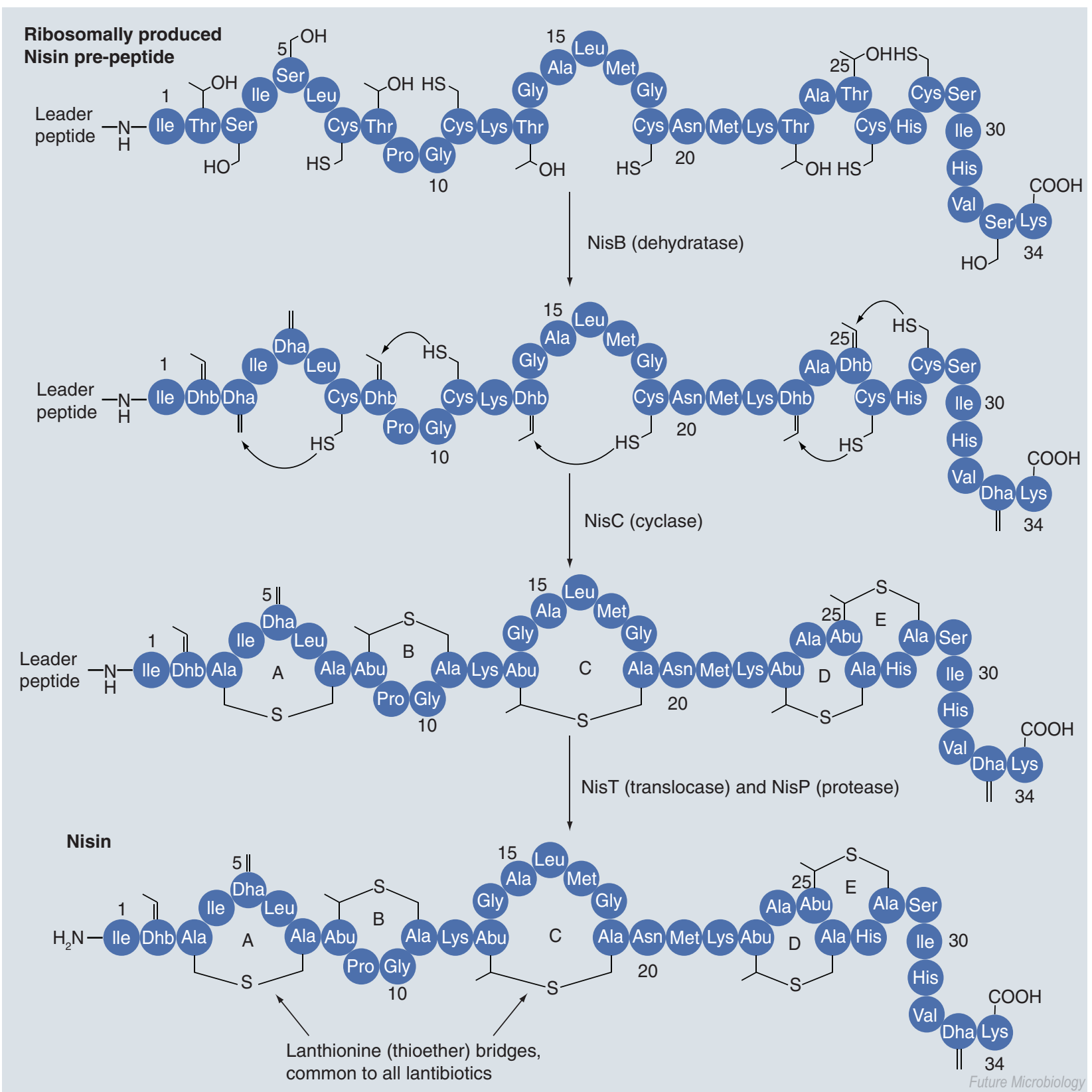

The ribosomally produced nisin prepeptide is enzymatically modified to yield the mature lantibiotic containing the unnatural amino acids Lan, MeLan, Dha and Dhb. 


\section{Lantibiotic mode of action Nisin \& the type A lantibiotics}

Nisin is comprised of 34 amino acids and at physiological $\mathrm{pH}$ bears a net positive charge $(+4)$. Of the five lanthionine-based rings in the peptide core of nisin, the $\mathrm{A}, \mathrm{B}$ and $\mathrm{C}$ rings are separated from rings $\mathrm{D}$ and $\mathrm{E}$ by a flexible 'hinge' region (residues 20-22). Despite being the oldest known antibiotic, the precise mode of action by which nisin operates has only recently been brought to light. It was initially suggested that nisin killed bacteria via binding to lipid II in a manner similar to that described for vancomycin $[60,61]$. However, unlike vancomycin, nisin was later shown to cause the rapid outflow of small cytoplasmic compounds such as amino acids, ATP or preaccumulated rubidium, as well as the collapse of vital ion gradients, when administered to Gram-positive bacteria [50,62]. These results supported a mode of action involving perturbation of the plasma membrane. Further experiments, focusing on the interaction of the cationic nisin with model membranes containing anionic lipids found in the plasma membrane of Gram-positive bacteria [63-66], led to a perplexing observation: while the concentration of nisin required for membrane perturbation in model experiments was in the micromolar range, the concentration at which nisin was able to effectively kill bacteria was in the nanomolar range. These results were ultimately reconciled by experiments that showed nisin has a twofold mode of action whereby it uses lipid II as a 'docking molecule' to form pores in bacterial membranes in a targeted manner and with high efficiency $[67,68]$. It has also since been shown that the pores formed by nisin in membranes containing lipid II are much more stable than pores formed in the absence of the receptor [69-72]. Furthermore, two independent approaches have demonstrated that lipid II is a constituent of the pore complex [73,74], the stoichiometry of which is four lipid II molecules and eight nisin molecules (Figure 6) [75].

Recently, NMR investigations have provided molecular-level insight into the interaction of nisin with lipid II [76]. This work showed that nisin has a unique mode of binding to lipid II, entirely different from glycopeptides (as earlier indicated in Figure 2). A defined network of five intermolecular hydrogen bonds between nisin's peptide backbone and the pyrophosphate moiety

\section{Figure 6. Model for the target-directed pore-formation mechanism of nisin.}

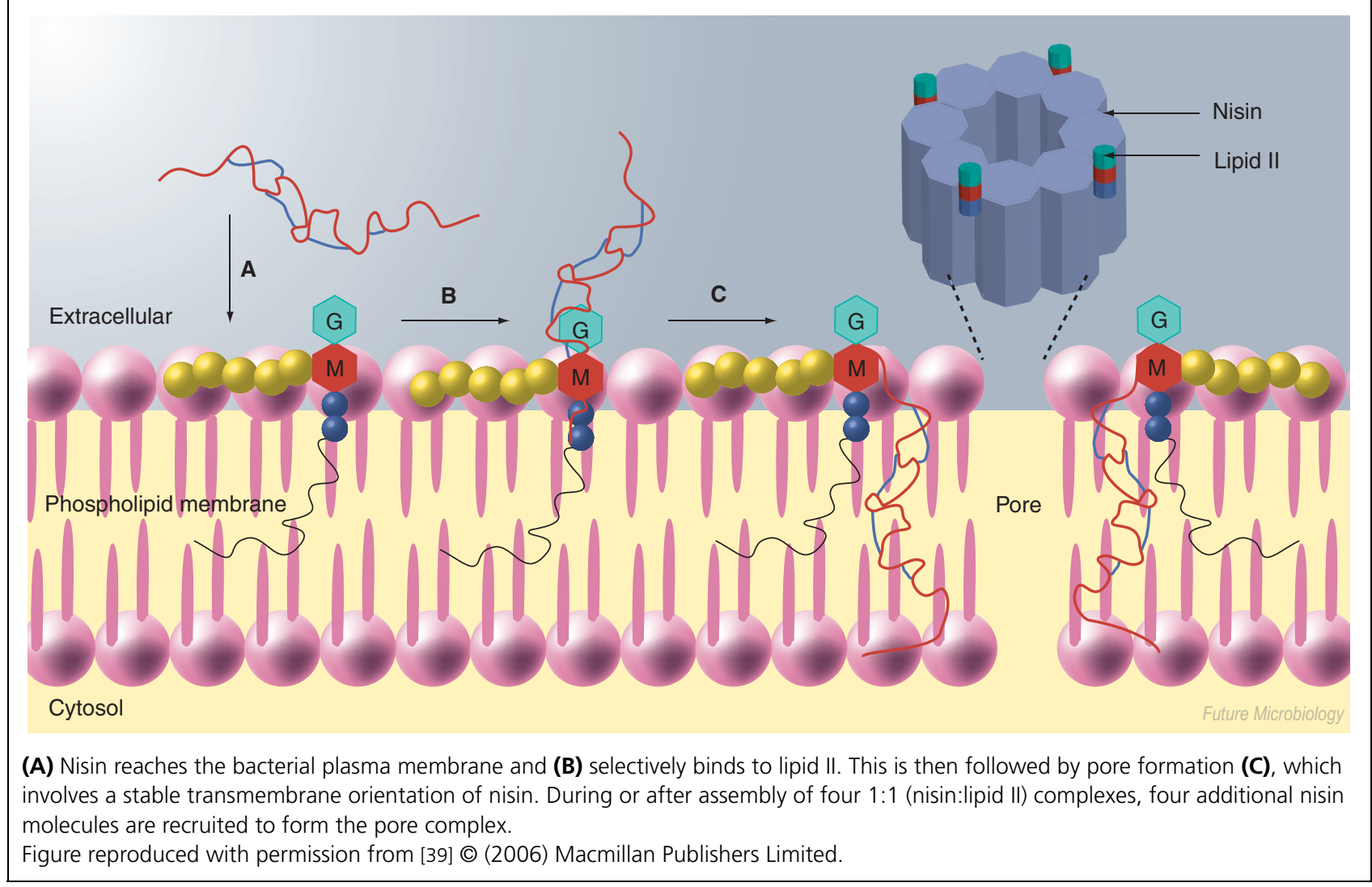


Figure 7. Hydrogen-bonding network between nisin $\mathrm{N}$-terminal residues and lipid II pyrophosphate moiety.

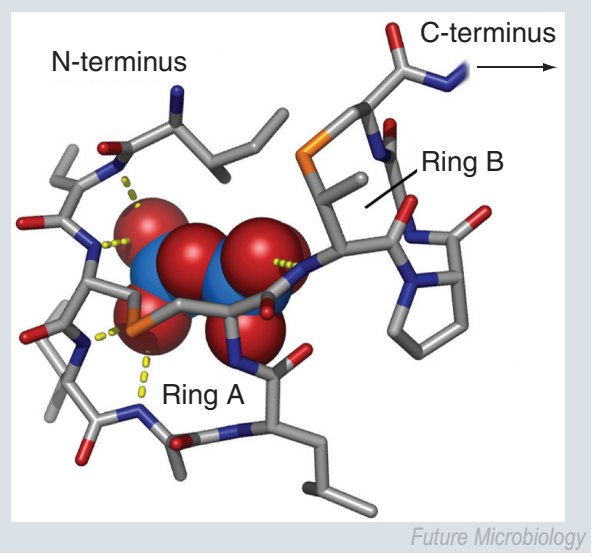

For clarity, only the pyrophosphate moiety of lipid II is shown, as a red and blue ball representation. Yellow dashes indicate intermolecular hydrogen bonds. Adapted from published coordinates [76].

of lipid II are responsible for the association (Figure 7). Interestingly, only the first ten $\mathrm{N}$-terminal amino acids, containing lanthionine rings $\mathrm{A}$ and $\mathrm{B}$, contribute to the 'pyrophosphate cage' with which nisin binds lipid II. Nisin's lanthionine rings are critical to its biological activity and likely provide a pre-ordered structure with a lower entropic cost upon binding to lipid II [77].

The $\mathrm{N}$-terminal A/B lanthionine ring system of nisin is also maintained in a number of other lantibiotics, which suggests that these peptides also interact with lipid II in a similar manner (Figure 8). The closest relative of nisin, subtilin, differs at three places in the first eleven residues of the sequence. However, these three places

Figure 8. A/B ring system homology between nisin and related lantibiotics.

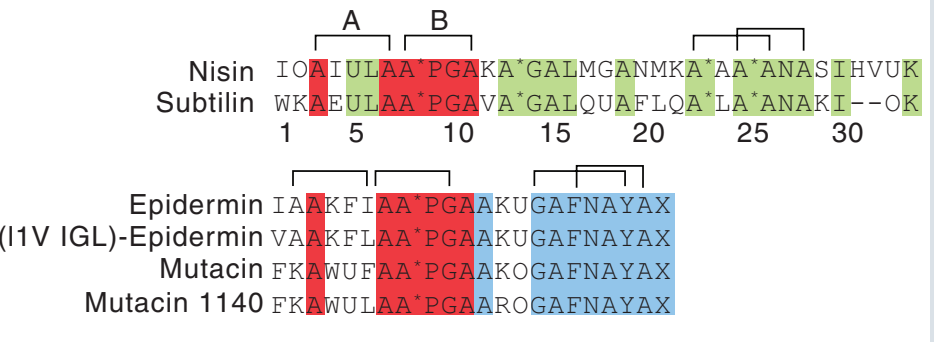

Red denotes homology between the nisin and epidermin families, green within the nisin family and blue within the epidermin family. are not key positions, and thus the cage structure remains intact with only the side chains differing.

Members of the epidermin family of lantibiotics also share the nisin $\mathrm{A} / \mathrm{B}$ ring system, suggesting a lipid II-mediated mode of action. The epidermins are highly potent antibiotics with MIC values comparable to nisin [78]. However, these peptides are of insufficient length to span a bacterial membrane and cannot induce leakage from model membrane systems in the presence of lipid II. Recent fluorescence microscopy experiments have suggested that the epidermins functions to sequester lipid II in a unique manner, effectively removing it from the cell division site (septum) and blocking peptidogylan synthesis [79].

\section{Mersacidin \& the type B lantibiotics}

Mersacidin is the most studied of the type $B$ lantibiotics (Figure 9). While smaller and more compact in structure, this class of lantibiotic also targets lipid II and inhibits bacterial cellwall synthesis (without pore-formation as for nisin) [80].

The lipid II-binding interaction of mersacidin is different to that of nisin and includes the terminal GlcNAc sugar [80]. Comparison of mersacidin with similar lantibiotics reveals a conserved sequence that comprises residues $12-18$, suggesting that these residues may form the core lipid II-binding site. While the measured affinity of mersacidin for purified lipid II is much lower than that of nisin $[80,81]$, it remains a potent antibiotic indicating that additional factors likely contribute to its overall antibacterial mode of action [67,81].

\section{Lacticin 3147 \& the} two-component lantibiotics

The two-component lantibiotics are comprised of two structurally unique peptides that act in synergy to provide potent antibacterial activity $[82,83]$. Lacticin 3147-A1/A2 (A1 and A2 referring to the two peptides) is the best-studied member of this class and was the first two-component lantibiotic system to be fully characterized at the structural level (Figure 10) [84,85].

In the case of lacticin 3147 , both the A1 and A2 peptides show modest antibacterial activity when administered in isolation. When coadministered however, a synergistic effect is observed with the resulting antibiotic activity many-fold greater than the sum of the individual activities (Figure 11). 


\section{Figure 9. Mersacidin, a type B lantibiotic.}

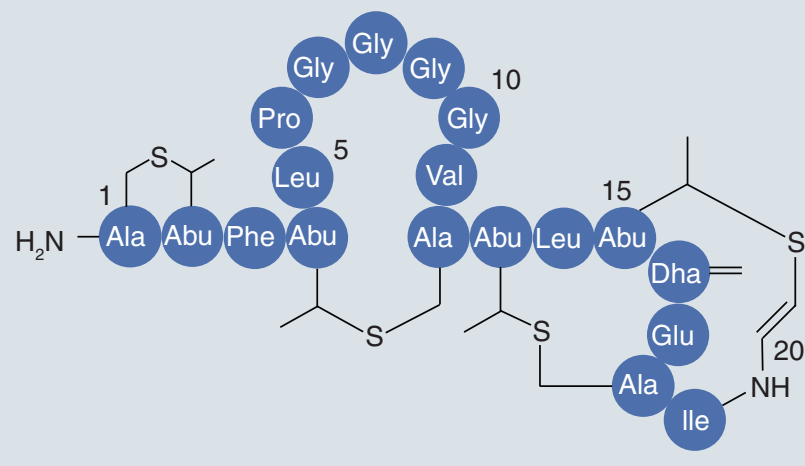

Recent investigations have provided insight into the lipid II-mediated mode of action for lacticin 3147 and show that when administered together, the two peptides cause pore formation in bacterial membranes in a manner reminiscent of nisin [86]. The model proposed involves a sequence of events in which the A1 peptide of lacticin binds first to lipid II to generate a binding site for the A2 peptide. The subsequent binding of the A2 peptide drives the system towards pore formation.
The apparent rarity of two-component lantibiotics is most likely due to the fact that investigators have traditionally been biased towards looking for single active compounds. With the identification of four new two-component lantibiotics in the past 2 years, seven such systems have now been documented [87-93], suggesting that two-component lantibiotics may indeed be more common than previously realized.

\section{Lantibiotic-resistance mechanisms}

Investigations into the acquired bacterial resistance to lantibiotics have primarily focused on nisin. It has been shown that many nisin-sensitive Grampositive bacteria, including clinically relevant strains, can acquire nisin resistance upon repeated exposure to increasing nisin concentrations $[10,44,94,95]$. This type of resistance is often lost once nisin pressure is removed [10] and is more accurately described as a physiological adaptation, although the nisin resistance of Streptococcus bovis was claimed to be stable, resistant cells were rapidly overgrown by sensitive ones [94]. Unlike vancomycin resistance, this adaptive mechanism does not involve an alteration of either the structure or

\section{Figure 10. Structures of the lacticin 3147 (A) A1 and (B) A2 lantibiotic peptides.}

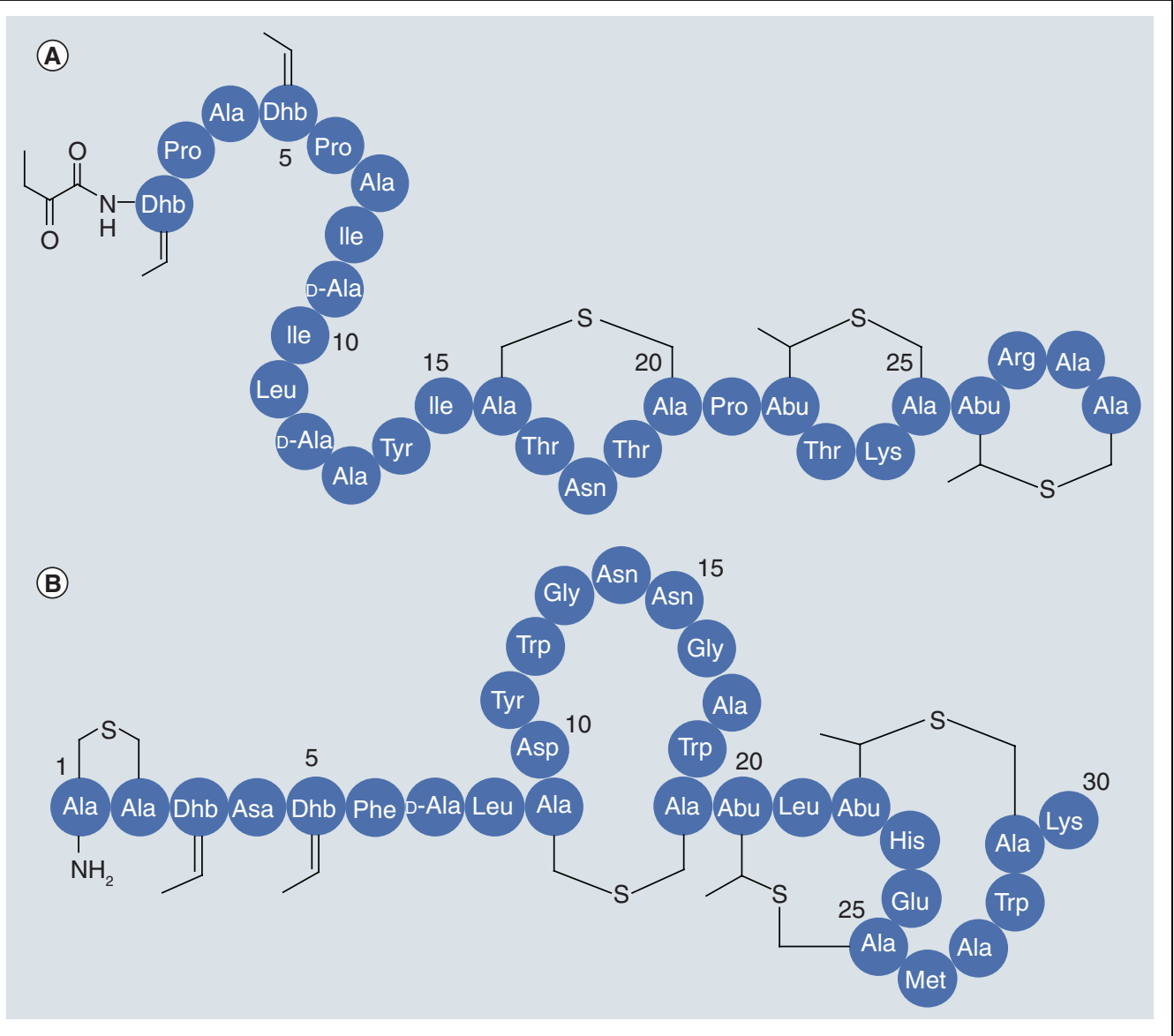


Figure 11. Complementary activity of lacticin 3147-A1 and -A2 against Lactococcus lactis subsp. cremoris HP.

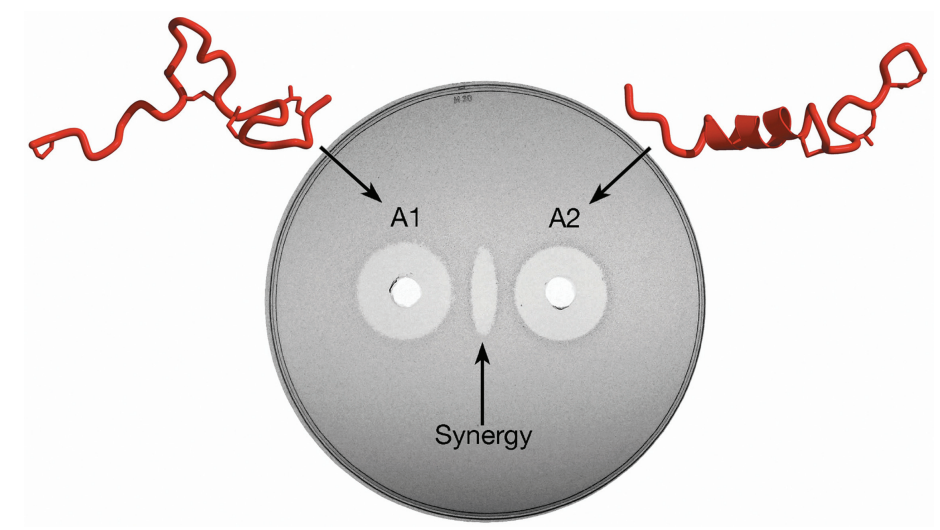

The synergy of the peptides is apparent when they are spotted at identical concentrations side-by-side. Both peptides form an inhibition zone of approximately the same size, and an extra inhibition zone has become visible that is clearly resolved from the inhibition zones of the individual peptides. Herein, the two peptides have diffused towards each other, and the synergetic effect becomes visible. This phenomenon is not observed if the A1 or A2 peptides are spotted next to themselves alone.

quantity of lipid II. Rather, lipid II is effectively 'shielded' from nisin by a change in the cell-wall composition [10,94,96-99]. Normally, the cell wall of a Gram-positive bacterium is highly negatively charged due to the phosphate groups of teichoic acid, another major component of the cell wall (Figure 12).

Teichoic acids are either covalently linked to the peptidoglycan layer (as in Figure 12), or membrane linked via a lipid anchor. A variety of substituents can be attached to the negatively charged phosphoglycerol moiety, one of which is D-ala. Incorporation of D-ala into teichoic acid reduces the net negative charge of the cell wall and has recently been shown to be a major cause of nisin resistance in strains of S. bovis, Lactococcus lactis and Bacillus subtilis [94,100,101]. Strains displaying elevated levels of D-Ala containing teichoic acids also exhibited an upregulation of the dlt operon which regulates D-Ala incorporation [101,102]. These results indicate that the main bacterial adaptation leading to nisin resistance involves an electrostatic shielding mechanism; incorporation of positive charges in the cell wall serve to repel nisin, preventing it from reaching lipid II.

\section{Conclusion}

Lantibiotics target lipid II in a variety of ways and operate with several modes of action. To date, all lantibiotics tested show promising in vitro activity against multiple-drug-resistant and vancomycin-resistant strains. Lipid II is a uniquely prokaryotic biomolecule with no known metabolic role in humans, and as such represents a promising target for the development of selective antibiotics with low toxicity. While certain pharmacokinetic obstacles remain to be fully addressed, the clinical development of lantibiotics may benefit from the information gleaned from the use of nisin in the food industry as a preservative, on issues relating to formulation, conditions of use and stability. Also, with the rapidly increasing body of knowledge pertaining to the structures and of the modes of action of these peptides, it should be possible to modify lantibiotics to circumvent these barriers. The clinical development of the lipid-II-targeting lantibiotics is likely to play an important role in future approaches to dealing with infectious disease.

Figure 12. (A) Cell wall-associated teichoic acid structure in nisin-sensitive organisms and (B) D-Ala modified teichoic acid with reduced net negative charge as found in nisin-resistant bacteria.

(A)

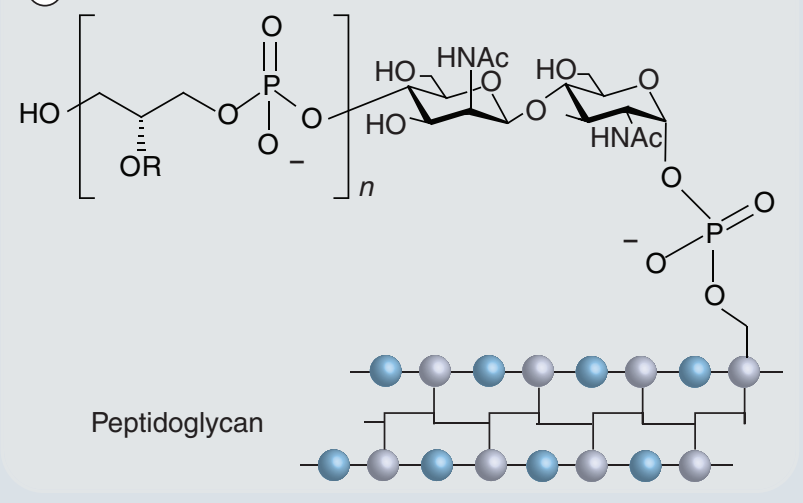

(B) Teichoic acid

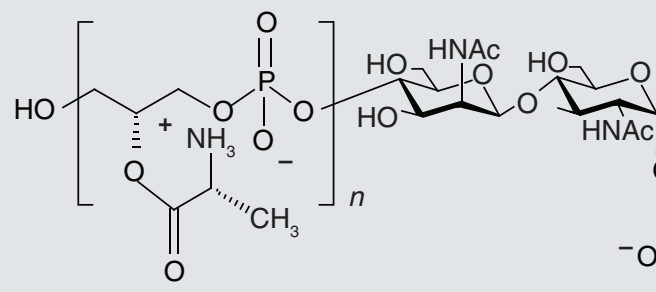

Peptidoglycan 
Financial \& competing interests disclosure

The authors have no relevant affiliations or financial involvement with any organization or entity with a financial interest in or financial conflict with the subject matter or materials dis-cussed in the manuscript. This includes employ-ment, consultancies, honoraria, stock ownership or options, expert testimony, grants or patents received or pending, or royalties. The authors gratefully acknowledge the assistance of Ms Micah A Walker in the preparation and editing of this manuscript.

\section{Executive summary}

\section{The expanding role of lipid II as a target for lantibiotics}

- This review describes recent progress made in understanding the lipid II-associated antibacterial characteristics of a variety of naturally occurring compounds, with particular focus on the lantibiotic peptides.

\section{Lantibiotic mode of action}

- There is growing evidence to support a lipid II-associated mode of action by which lantibiotics specifically target bacteria.

- The interaction of nisin with lipid II (recently characterized at the molecular level by nuclear magnetic resonance spectroscopy) provides insight into approaches for targeting bacteria that are unique from those employed by conventional antibiotics.

\section{Future perspective}

- While pharmacokinetic obstacles remain to be fully addressed, the clinical development of lipid II-targeting lantibiotics is likely to play an important role in future approaches to dealing with infectious disease.

\section{Bibliography}

1. Payne DJ, Gwynn MN, Holmes DJ, Pompliano DL: Drugs for bad bugs: confronting the challenges of antibacterial discovery. Nat. Rev. Drug Discov. 6, 29-40 (2007).

2. Harz H, Burgdorf $\mathrm{K}$, Holtje JV: Isolation and separation of the glycan strands from murein of Escherichia coli by reversed-phase high-performance liquid chromatography. Anal. Biochem. 190, 120-128 (1990).

3. Lovering AL, de Castro LH, Lim D, Strynadka NC: Structural insight into the transglycosylation step of bacterial cell-wall biosynthesis. Science 315, 1402-1405 (2007).

4. Yuan Y, Barrett D, Zhang Y, Kahne D, Sliz P, Walker S: Crystal structure of a peptidoglycan glycosyltransferase suggests a model for processive glycan chain synthesis. Proc. Natl Acad. Sci. USA 104, 5348-5353 (2007).

5. Walsh C: In: Antibiotics: Actions, Origins, Resistance. ASM Press, Washington DC, USA (2003).

6. van Heijenoort J: Recent advances in the formation of the bacterial peptidoglycan monomer unit. Nat. Prod. Rep. 18, 503-519 (2001).

7. Lazar K, Walker S: Substrate analogues to study cell-wall biosynthesis and its inhibition. Curr. Opin. Chem. Biol. 6, 786-793 (2002).

8. van Dam V, Sijbrandi R, Kol M, Swiezewska E, de Kruijff B, Breukink E: Transmembrane transport of peptidoglycan precursors across model and bacterial membranes. Mol. Microbiol. 64, 1105-1114 (2007).
9. Labischinski H, Goodell EW, Goodell A, Hochberg ML: Direct proof of a 'more-than-single-layered' peptidoglycan architecture of Escherichia coli W7: a neutron small-angle scattering study. J. Bacteriol. 173, 751-756 (1991).

10. Kramer NE, Smid EJ, Kok J, de Kruijff B, Kuipers OP, Breukink E: Resistance of Gram-positive bacteria to nisin is not determined by lipid II levels. FEMS Microbiol. Lett. 239, 157-161 (2004).

11. Stone K, Strominger JL: Binding of bacitracin to cells and protoplasts of Micrococcus lysodeikticus. J. Biol. Chem. 249, 1823-1827 (1974).

12. McCloskey MA, Troy FA: Paramagnetic isoprenoid carrier lipids. 1. Chemical synthesis and incorporation into model membranes. Biochemistry 19, 2056-2060 (1980)

13. McCormick MH, McGuire JM, Pittenger GE, Pittenger RC, Stark WM: Vancomycin, a new antibiotic. I. Chemical and biologic properties. Antibiot. Annu. 3, 606-611 (1955).

14. Widboom PF, Fielding EN, Liu Y, Bruner SD: Structural basis for cofactor-independent dioxygenation in vancomycin biosynthesis. Nature 447 , 342-345 (2007).

15. Zerbe K, Woithe K, Li DB, Vitali F, Bigler L, Robinson JA: An oxidative phenol coupling reaction catalyzed by oxyB, a cytochrome $\mathrm{P} 450$ from the vancomycin-producing microorganism. Angew. Chem. Int. Ed. Engl. 43, 6709-6713 (2004)
16. Woithe K, Geib N, Zerbe K et al:: Oxidative phenol coupling reactions catalyzed by OxyB: a cytochrome P450 from the vancomycin producing organism. Implications for vancomycin biosynthesis. J. Am. Chem. Soc. 129, 6887-6895 (2007).

17. Williamson MP, Williams DH: Structure revision of the antibiotic vancomycin. Use of nuclear Overhauser effect difference spectroscopy. J. Am. Chem. Soc. 103, 6580-6585 (1981).

18. Sheldrick GM, Jones PG, Kennard O, Williams DH, Smith GA: Structure of vancomycin and its complex with acetyl-Dalanyl-D-alanine. Nature 271, 223-225 (1978).

19. Harris CM, Harris TM: Structure of the glycopeptide antibiotic vancomycin. Evidence for an asparagine residue in the peptide. J. Am. Chem. Soc. 104, 4293-4295 (1982).

20. Perkins HR: Specificity of combination between mucopeptide precursors and vancomycin or ristocetin. Biochem. J. 111, 195-205 (1969).

21. Chatterjee AN, Perkins HR: Compounds formed between nucleotides related to the biosynthesis of bacterial cell wall and vancomycin. Biochem. Biophys. Res. Commun. 24, 489-494 (1966).

22. Molinari H, Pastore A, Lian LY, Hawkes GE, Sales K: Structure of vancomycin and a vancomycin/D-Ala-D-Ala complex in solution. Biochemistry 29, 2271-2277 (1990).

23. Vollmerhaus PJ, Breukink E, Heck AJ Getting closer to the real bacterial cell wall target: biomolecular interactions of watersoluble lipid II with glycopeptide antibiotics. Chemistry 9, 1556-1565 (2003). 
24. Arthur M, Courvalin P: Genetics and mechanisms of glycopeptide resistance in enterococci. Antimicrob. Agents Chemother. 37, 1563-1571 (1993).

25. Appelbaum PC: The emergence of vancomycin-intermediate and vancomycinresistant Staphylococcus aureus. Clin. Microbiol. Infect. 12(Suppl. 1), 16-23 (2006).

26. Appelbaum PC, Jacobs MR: Recently approved and investigational antibiotics for treatment of severe infections caused by Grampositive bacteria. Curr. Opin. Microbiol. 8, 510-517 (2005).

27. Johnson AP, Uttley AH, Woodford N, George RC: Resistance to vancomycin and teicoplanin: an emerging clinical problem. Clin. Microbiol. Rev. 3, 280-291 (1990).

28. Malabarba A, Goldstein BP: Origin, structure, and activity in vitro and in vivo of dalbavancin. J. Antimicrob. Chemother. 55(Suppl. 2) ii15-ii20 (2005).

29. Higgins DL, Chang R, Debabov DV et al: Telavancin, a multifunctional lipoglycopeptide, disrupts both cell wall synthesis and cell membrane integrity in methicillin-resistant Staphylococcus aureus. Antimicrob. Agents Chemother. 49, 1127-1134 (2005).

30. Mercier RC, Hrebickova L: Oritavancin: a new avenue for resistant Gram-positive bacteria. Expert Rev. Anti. Infect. Ther. 3, 325-332 (2005).

31. McCafferty DG, Cudic P, Frankel BA, Barkallah S, Kruger RG, Li W: Chemistry and biology of the ramoplanin family of peptide antibiotics. Biopolymers 66 , 261-284 (2002)

32. Walker S, Chen L, Hu Y, Rew Y, Shin D, Boger DL: Chemistry and biology of ramoplanin: a lipoglycodepsipeptide with potent antibiotic activity. Chem. Rev. 105, 449-476 (2005)

33. Helm JS, Chen L, Walker S: Rethinking ramoplanin: the role of substrate binding in inhibition of peptidoglycan biosynthesis. J. Am. Chem. Soc. 124, 13970-13971 (2002).

34. Singh MP, Petersen PJ, Weiss WJ et al: Mannopeptimycins, new cyclic glycopeptide antibiotics produced by Streptomyces hygroscopicus LL-AC98: antibacterial and mechanistic activities. Antimicrob. Agents Chemother. 47, 62-69 (2003).

35. Ruzin A, Singh G, Severin A et al:: Mechanism of action of the mannopeptimycins, a novel class of glycopeptide antibiotics active against vancomycin-resistant Gram-positive bacteria. Antimicrob. Agents Chemother. 48, 728-738 (2004)
36. Shoji J, Hinoo H, Katayama T et al:: Isolation and characterization of new peptide antibiotics, plusbacins A1-A4 and B1--B4. J. Antibiot. (Tokyo) 45, 817-823 (1992).

37. Maki H, Miura K, Yamano Y: Katanosin B and plusbacin $\mathrm{A}(3)$, inhibitors of peptidoglycan synthesis in methicillinresistant Staphylococcus aureus. Antimicrob. Agents Chemother. 45, 1823-1827 (2001).

38. Shoji J, Hinoo H, Matsumoto K et al:: Isolation and characterization of katanosins A and B. J. Antibiot. (Tokyo) 41, 713-718 (1988).

39. Breukink E, de Kruijff B: Lipid II as a target for antibiotics. Nat. Rev. Drug Discov. 5 , 321-332 (2006).

40. Twomey D, Ross RP, Ryan M, Meaney B, Hill C: Lantibiotics produced by lactic acid bacteria: structure, function and applications. Antonie Van Leeuwenhoek 82, 165-185 (2002).

41. McAuliffe O, Ross RP, Hill C: Lantibiotics: structure, biosynthesis and mode of action. FEMS Microbiol. Rev. 25, 285-308 (2001).

42. Rogers LA: The inhibiting effect of Streptococcus lactis on Lactobacillus bulgaricus. J. Bacteriol. 16, 321-325 (1928).

43. Brumfitt W, Salton MR, Hamilton-Miller JM: Nisin, alone and combined with peptidoglycan-modulating antibiotics: activity against methicillin-resistant Staphylococcus aureus and vancomycin-resistant enterococci. J. Antimicrob. Chemother. 50, 731-734 (2002).

44. Severina E, Severin A, Tomasz A: Antibacterial efficacy of nisin against multidrug-resistant Gram-positive pathogens. J. Antimicrob. Chemother. 41, 341-347 (1998).

45. Mota-Meira M, LaPointe G, Lacroix C, Lavoie MC: MICs of mutacin B-Ny266, nisin A, vancomycin, and oxacillin against bacterial pathogens. Antimicrob. Agents Chemother. 44, 24-29 (2000).

46. Stevens KA, Sheldon BW, Klapes NA, Klaenhammer TR: Nisin treatment for inactivation of Salmonella species and other Gram-negative bacteria. Appl. Environ. Microbiol. 57, 3613-3615 (1991).

47. Chatterjee $\mathrm{S}$, Chatterjee DK, Jani RH et al: Mersacidin, a new antibiotic from Bacillus. In vitro and in vivo antibacterial activity. J. Antibiot. (Tokyo) 45, 839-845 (1992).

48. Kruszewska D, Sahl HG, Bierbaum G, Pag U, Hynes SO, Ljungh A: Mersacidin eradicates methicillin-resistant Staphylococcus aureus (MRSA) in a mouse rhinitis model. J. Antimicrob. Chemother. 54, 648-653 (2004).
49. Guder A, Wiedemann I, Sahl HG: Posttranslationally modified bacteriocins the lantibiotics. Biopolymers 55, 62-73 (2000).

50. Jung G, Sahl HG: In: Nisin and Novel Lantibiotics. Escom Publishers, Leiden, The Netherlands (1991).

51. Chatterjee C, Paul M, Xie L, van der Donk WA: Biosynthesis and mode of action of lantibiotics. Chem. Rev. 105, 633-684 (2005).

52. Cotter, PD, Hill C, Ross RP: Bacterial lantibiotics: strategies to improve therapeutic potential. Curr. Protein Pept. Sci. 6, 61-75 (2005).

53. Schnell N, Entian KD, Schneider U et al:: Prepeptide sequence of epidermin, a ribosomally synthesized antibiotic with four sulphide-rings. Nature 333, 276-278 (1988).

54. Xie L, Miller LM, Chatterjee C, Averin O, Kelleher Nl, van der Donk WA: Lacticin 481: in vitro reconstitution of lantibiotic synthetase activity. Science 303, 679-681 (2004).

55. Li B, Yu JP, Brunzelle JS, Moll GN, van der Donk WA, Nair SK: Structure and mechanism of the lantibiotic cyclase involved in nisin biosynthesis. Science 311, 1464-1467 (2006).

56. Rince A, Dufour A, Le Pogam $S$, Thuault D, Bourgeois CM, Le Pennec JP: Cloning, expression, and nucleotide sequence of genes involved in production of lactococcin DR, a bacteriocin from lactococcus lactis subsp. lactis. Appl. Environ. Microbiol. 60, 1652-1657 (1994).

57. Uguen P, Le Pennec JP, Dufour A: Lantibiotic biosynthesis: interactions between prelacticin 481 and its putative modification enzyme, LctM. J. Bacteriol. 182, 5262-5266 (2000).

58. Dufour A, Hindre T, Haras D, Le Pennec JP: The biology of lantibiotics from the lacticin 481 group is coming of age. FEMS Microbiol. Rev. 31, 134-167 (2007).

59. You YO, van der Donk WA: Mechanistic investigations of the dehydration reaction of lacticin 481 synthetase using site-directed mutagenesis. Biochemistry 46, 5991-6000 (2007).

60. Linnett PE, Strominger JL: Additional antibiotic inhibitors of peptidoglycan synthesis. Antimicrob. Agents Chemother. 4, 231-236 (1973).

61. Reisinger P, Seidel H, Tschesche H, Hammes WP: The effect of nisin on murein synthesis. Arch. Microbiol. 127, 187-193 (1980). 
62. Ruhr E, Sahl HG: Mode of action of the peptide antibiotic nisin and influence on the membrane potential of whole cells and on cytoplasmic and artificial membrane vesicles. Antimicrob. Agents Chemother. 27, 841-845 (1985).

63. Garcera MJ, Elferink MG, Driessen AJ, Konings WN: In vitro pore-forming activity of the lantibiotic nisin. Role of protonmotive force and lipid composition. Eur. J. Biochem. 212, 417-422 (1993).

64. Breukink E, van Kraaij C, Demel RA, Siezen RJ, Kuipers OP, de Kruijff B: The C-terminal region of nisin is responsible for the initial interaction of nisin with the target membrane. Biochemistry 36, 6968-6976 (1997).

65. Breukink E, Ganz P, de Kruijff B, Seelig J: Binding of Nisin $\mathrm{Z}$ to bilayer vesicles as determined with isothermal titration calorimetry. Biochemistry 39, 10247-10254 (2000).

66. Martin I, Ruysschaert JM, Sanders D, Giffard CJ: Interaction of the lantibiotic nisin with membranes revealed by fluorescence quenching of an introduced tryptophan. Eur. J. Biochem. 239, 156-164 (1996).

67. Brotz H, Josten M, Wiedemann I et al.: Role of lipid-bound peptidoglycan precursors in the formation of pores by nisin, epidermin and other lantibiotics. Mol. Microbiol. 30, 317-327 (1998).

68. Breukink E, Wiedemann I, van Kraaij C, Kuipers OP, Sahl H, de Kruijff B: Use of the cell wall precursor lipid II by a pore-forming peptide antibiotic. Science 286, 2361-2364 (1999).

69. Breukink E, van Kraaij C, van Dalen A et al:: The orientation of nisin in membranes. Biochemistry 37, 8153-8162 (1998).

70. Sahl HG, Kordel M, Benz R: Voltagedependent depolarization of bacterial membranes and artificial lipid bilayers by the peptide antibiotic nisin. Arch. Microbiol. 149, 120-124 (1987).

71. van Heusden HE, de Kruijff B, Breukink E: Lipid II induces a transmembrane orientation of the pore-forming peptide lantibiotic nisin. Biochemistry 41, 12171-12178 (2002)

72. Wiedemann I, Benz R, Sahl HG: Lipid IImediated pore formation by the peptide antibiotic nisin: a black lipid membrane study. J. Bacteriol. 186, 3259-3261 (2004).

73. Breukink E, van Heusden HE, Vollmerhaus PJ et al.: Lipid II is an intrinsic component of the pore induced by nisin in bacterial membranes. J. Biol. Chem. 278, 19898-19903 (2003).
74. Bonev BB, Breukink E, Swiezewska E, De Kruijff B, Watts A: Targeting extracellular pyrophosphates underpins the high selectivity of nisin. FASEB J. 18, 1862-1869 (2004)

75. Hasper HE, de Kruijff B, Breukink E: Assembly and stability of nisin-lipid II pores. Biochemistry 43, 11567-11575 (2004)

76. Hsu ST, Breukink E, Tischenko E et al:: The nisin-lipid II complex reveals a pyrophosphate cage that provides a blueprint for novel antibiotics. Nat. Struct. Mol. Biol. 11, 963-967 (2004).

77. Wiedemann I, Breukink E, van Kraaij C et al: Specific binding of nisin to the peptidoglycan precursor lipid II combines pore formation and inhibition of cell wall biosynthesis for potent antibiotic activity. J. Biol. Chem. 276, 1772-1779 (2001).

78. Bonelli RR, Schneider T, Sahl HG, Wiedemann I: Insights into in vivo activities of lantibiotics from gallidermin and epidermin mode-of-action studies. Antimicrob. Agents Chemother. 50, 1449-1457 (2006).

79. Hasper HE, Kramer NE, Smith JL et al: An alternative bactericidal mechanism of action for lantibiotic peptides that target lipid II. Science 313, 1636-1637 (2006).

80. Brotz H, Bierbaum G, Leopold K, Reynolds PE, Sahl HG: The lantibiotic mersacidin inhibits peptidoglycan synthesis by targeting lipid II. Antimicrob. Agents Chemother. 42, 154-160 (1998).

81. Hsu ST, Breukink E, Bierbaum G et al.: NMR study of mersacidin and lipid II interaction in dodecylphosphocholine micelles. Conformational changes are a key to antimicrobial activity. J. Biol. Chem. 278, 13110-13117 (2003).

82. Garneau S, Martin NI, Vederas JC: Two-peptide bacteriocins produced by lactic acid bacteria. Biochimie 84, 577-592 (2002).

83. O'Connor EB, Cotter PD, O'Connor P et al: Relatedness between the two-component lantibiotics lacticin 3147 and staphylococcin C55 based on structure, genetics and biological activity. BMC Microbiol. 7, 24 (2007).

84. Martin NI, Sprules T, Carpenter MR et al:: Structural characterization of lacticin 3147 , a two-peptide lantibiotic with synergistic activity. Biochemistry 43, 3049-3056 (2004).

85. Cotter PD, Deegan LH, Lawton EM et al. Complete alanine scanning of the twocomponent lantibiotic lacticin 3147: generating a blueprint for rational drug design. Mol. Microbiol. 62, 735-747 (2006).
86. Wiedemann I, Bottiger T, Bonelli R et al: The mode of action of the lantibiotic lacticin 3147 - a complex mechanism involving specific interaction of two peptides and the cell wall precursor lipid II. Mol. Microbiol. 61, 285-296 (2006).

87. Cox CR, Coburn PS, Gilmore MS: Enterococcal cytolysin: a novel two component peptide system that serves as a bacterial defense against eukaryotic and prokaryotic cells. Curr. Protein Pept. Sci. 6, 77-84 (2005).

88. Ryan MP, Jack RW, Josten M et al:: Extensive post-translational modification, including serine to D-alanine conversion, in the twocomponent lantibiotic, lacticin 3147. J. Biol. Chem. 274, 37544-37550 (1999).

89. Holo H, Jeknic Z, Daeschel M, Stevanovic S, Nes IF: Plantaricin W from Lactobacillus plantarum belongs to a new family of two-peptide lantibiotics. Microbiology 147, 643-651 (2001).

90. Navaratna MA, Sahl HG, Tagg JR: Twocomponent anti-Staphylococcus aureus lantibiotic activity produced by Staphylococcus aureus C55. Appl. Environ. Microbiol. 64, 4803-4808 (1998).

91. Yonezawa H, Kuramitsu HK: Genetic analysis of a unique bacteriocin, $\mathrm{Smb}$, produced by Streptococcus mutans GS5. Antimicrob. Agents Chemother. 49, 541-548 (2005).

92. Hyink O, Balakrishnan M, Tagg JR: Streptococcus rattus strain BHT produces both a class I two-component lantibiotic and a class II bacteriocin. FEMS Microbiol. Lett. 252, 235-241 (2005).

93. McClerren AL, Cooper LE, Quan C, Thomas PM, Kelleher NL, van der Donk WA: Discovery and in vitro biosynthesis of haloduracin, a twocomponent lantibiotic. Proc. Natl Acad. Sci. USA 103, 17243-17248 (2006).

94. Mantovani HC, Russell JB: Nisin resistance of Streptococcus bovis. Appl. Environ. Microbiol. 67, 808-813 (2001).

95. Breuer B, Radler F: Inducible resistance against nisin in Lactobacillus casei. Arch. Microbiology 165, 114 (1996).

96. Maisnier-Patin S, Richard J: Cell wall changes in nisin-resistant variants of Listeria innocua grown in the presence of high nisin concentrations. FEMS Microbiol. Lett. 140, 29-35 (1996).

97. Verheul A, Russell NJ, Van THR, Rombouts FM, Abee T: Modifications of membrane phospholipid composition in nisin-resistant Listeria monocytogenes Scott A. Appl. Environ. Microbiol. 63, 3451-3457 (1997). 
98. Crandall AD, Montville TJ: Nisin resistance in Listeria monocytogenes ATCC 700302 is a complex phenotype. Appl. Environ. Microbiol. 64, 231-237 (1998).

99. Davies EA, Falahee MB, Adams MR: Involvement of the cell envelope of Listeria monocytogenes in the acquisition of nisin resistance. J. Appl. Bacteriol. 81, 139-146 (1996).

100. Neuhaus FC, Baddiley J: A continuum of anionic charge: structures and functions of D-alanyl-teichoic acids in Gram-positive bacteria. Microbiol. Mol. Biol. Rev. 67, 686-723 (2003).
101. Kramer NE: Nisin resistance in Grampositive bacteria. Utrecht University (2005).

102. Cao M, Helmann JD: The Bacillus subtilis extracytoplasmic-function sigmaX factor regulates modification of the cell envelope and resistance to cationic antimicrobial peptides. J. Bacteriol. 186, 1136-1146 (2004).

\section{Affiliations}

- Nathaniel I Martin Utrecht University, Department of Medicinal Chemistry \& Chemical Biology and,
Department of Biochemistry \& Membranes, Sorbonnelaan 16, Room Z615, 3584 CA Utrecht, The Netherlands

Tel.: +31 30253 4232;

Fax: +31 30253 6655;

n.i.martin@uu.nl

- Eefjan Breukink

Utrecht University, Department of Biochemistry \& Membranes, Padualaan 8, 3584CH Utrecht, The Netherlands

e.j.breukink@chem.uu.nl 